\section{Inheritance of resistance to white mold disease in Phaseolus coccineus}

\author{
G. S. Abawi, R. Provvidenti, D. C. Crosier, \\ AND J. E. HUNTER
}

GEVERE EPIDEMICS of white mold of snap bean $\mathcal{O}$ (Phaseolus vulgaris L.), caused by Whetzelinia (=Sclerotinia) sclerotiorum (Lib) Korf and Dumont, have occurred repeatedly in central and western New York State in recent years. The disease has caused significant economic losses, especially during prolonged periods of wet weather ${ }^{1,12}$.

White mold epidemics in New York are initiated by ascospores produced mainly outside bean fields by sclerotia of the fungus '. Ascospores do not directly infect bean tissues in the prebloom stage, since blossoms are needed as an energy source for germination and infection ${ }^{1,5,10,12}$. A prolonged period of wet soil is required for the production of ascospores, and 48-72 hours of continuous moisture is required for initiation of infection ${ }^{1,9,10}$. The fungus completely colonizes mature and senescent blossoms in 2-3 days ${ }^{3}$. These infected blossoms then serve as an efficient source of inoculum when in contact with leaf, stem, and pod tissues. Chemical control of this disease with benomyl has been successful ${ }^{2,11,12}$, but its relatively high cost, the rigidity of the spray program, and the threat of the development of a benomyl-resistant strain of the pathogen have stimulated the search for sources of resistance in $P$. vulgaris and other Phaseolus species.

A large number of cultivars, breeding lines, and plant introductions were evaluated using an inoculation technique and conditions that simulated natural infection (Abawi et al. 4 ; Abawi et al., unpublished data). All the accessions of $P$. vulgaris were susceptible, although a few plants of some lines appeared to be tolerant. However, a high degree of resistance was found in selections of $P$. coccineus, including a white-flowered line, B-3749, a selection of P.I. 175829. This line and other accessions of $P$. coccineus had been found resistant to white mold by Adams et al. ${ }^{6}$ using a different inoculation procedure. Recently, Coyne et al. ${ }^{8}$ reported that Black Turtle Soup was the most resistant dry bean germplasm to the white mold fungus under natural inoculation conditions in western Nebraska.

This paper reports the inheritance of resistance in line B-3749 to $W$. sclerotiorum and the progress made in transferring the resistance to two commercial snap bean cultivars.

\section{Materials and Methods}

The genetic material used in this investigation was derived from crosses and backcrosses of B-3749 with Bush Blue Lake 274. Seeds of B-3749 were obtained

The authors are affiliated with the Department of Plant Pathology, New York State Agricultural Experiment Station, Cornell University, Geneva, New York 14456. from J.P. Meiners, Applied Plant Pathology Laboratory, USDA-ARS, Beltsville, Maryland. This line originally was obtained from J. Deakin, U.S. Vegetable Laboratory, Charleston, South Carolina.

Uniform germination was achieved by placing seeds on moist blotter paper in large plastic or glass petri dishes that were incubated for $3-5$ days at $25^{\circ} \mathrm{C}$. It often was necessary to slit the thick and leathery seed coat of B-3749 and its progenies to facilitate germination. Plants were grown singly in 5-inch clay pots and evaluated for resistance to the pathogen when they had reached the susceptible blossom stage.

Ascospores were derived from an isolate of $W$. sclerotiorum (large sclerotium type) collected in a bean field. For the production of apothecia, sclerotia were treated as previously described ${ }^{1,3}$. Ascospores were collected in sterile distilled water by applying about 5 psi suction ${ }^{13}$, and their concentration was adjusted with a Spencer hemacytometer. Initially, a concentration of 1-4 $\times 10^{4}$ ascospores $/ \mathrm{ml}$ was used, but later it was found that a concentration of about 2,000 ascospores/ml consistently caused a high level of infection. Approximately $2 \mathrm{ml}$ of a spore suspension were thoroughly atomized onto blossoms of each plant, using a pressure of 3 psi. Immediately afterwards, plants were placed in mist chambers at $21-25^{\circ} \mathrm{C}$ for one week. The misting cycle consisted of 3 minutes on and 3 minutes off. Disease severity was recorded using a scale of 0 to 5 . The criteria for each rating were as follows: 0) no apparent symptoms; 1) 1-3 arrested, small lesions; 2) one to several running lesions with moderate mycelial growth; 3) mycelial development involving up to 25 percent of the foliage; 4) extensive mycelial growth covering up to 50 percent of the foliage; and 5) death of the plant caused by massive mycelial growth. Plants scored 0 or 1 were considered resistant, those scored 2 to 5 were considered susceptible.

\section{Results}

The genetic basis for resistance to $W$. sclerotiorum in $P$. coccineus B-3749 is presented in Table $I$. Plants of B-3749 and its $F_{1}$ with Bush Blue Lake 274 were resistant after being inoculated twice.

Table I. Reaction of Phaseolus coccineus, B-3749 (P.I. 175829), and Phaseolus vulgaris, cultivar Bush Blue Lake 274, and their $\mathrm{F}_{1}, \mathrm{~F}_{2}, \mathrm{BC}_{1}$, and $\mathrm{BC}_{2}$ progenies to inoculation with $W$. sclerotiorum under mist chamber conditions in the greenhouse

\begin{tabular}{|c|c|c|c|c|}
\hline & \multicolumn{2}{|c|}{ No. plants } & \multirow{2}{*}{$\begin{array}{l}\text { Expected } \\
\text { ratio }\end{array}$} & \multirow{2}{*}{$\begin{array}{c}\text { Goodness } \\
\text { of-fit } \\
(P)\end{array}$} \\
\hline & res. & sus. & & \\
\hline P.I. 175829 & 41 & $\mathbf{0}$ & & \\
\hline Bush Blue Lake 274 & 0 & 112 & & \\
\hline$\left(B B L \times\right.$ P.I. 175829) $F_{1}$ & 5 & 0 & & \\
\hline $\begin{array}{l}\left(B B L \times \text { P.I. 175829) } F_{2}\right. \\
B B L \times(B B L\end{array}$ & 96 & 28 & $3: 1$ & 0.54 \\
\hline $\begin{array}{l}\times \text { P.I. 175829) } \mathrm{F}_{1} \\
\text { BBL } \times(\mathrm{BBL}\end{array}$ & 21 & 20 & $1: 1$ & 0.88 \\
\hline$\times$ P.I. 175829$) \mathrm{BC}_{1}$ & 18 & 19 & $1: 1$ & 0.88 \\
\hline
\end{tabular}


The ratio of resistant and susceptible plants in $F_{2}$ populations was close to a 3:1 segregation. Plants of both the first backcross and the second backcross to the susceptible parent segregated in a $1: 1$ ratio. Plants of Bush Blue Lake 274 became severely infected under the same conditions (Figure 1).

These data strongly indicate that resistance to $W$. sclerotiorum in plants of B-3749 is controlled by a single dominant factor. The symbol Ws (Whetzelinia sclerotiorum) is proposed for this gene.

\section{Discussion}

The ascospore inoculation procedure used in this study appears reliable and effective in detecting high levels of resistance to white mold. This method simulates the natural spread of the pathogen under New York conditions. However, because of the severity of this test, germplasm with a lower level of resistance may be lost. This method also does not detect germplasms that possess an avoidance mechanism against this disease. Coyne et al. ${ }^{7}$ and Steadman et al. ${ }^{14}$ have demonstrated that genetic modification of the architecture of the canopy of dry bean plants improves air circulation and causes a rapid drying of the plant surface, resulting in a reduction of severity of white mold under Nebraska conditions. The avoidance mechanism is an important and valid approach in dry regions of the United States, but it has limited application in the Northeast where extended rainy and long daily dew periods are prevalent throughout the growing season. However, the avoidance mechanism could be utilized in addition to the specific resistance to the pathogen found during this study.

The availability of a gene for resistance to white mold is of great economic significance and should be incorporated in many cultivars. The backcross program is well suited to transfer this genetic factor into commercial dry and snap bean lines since it is simply inherited. In our breeding program, several resistant plants with many desirable foliage and pod characteristics have been obtained in the first and second backcross using Bush Blue Lake 274 or Early Gallatin as recurrent parents. However, some difficulties were encountered in selfing plants of $\mathrm{F}_{1}$ of $P$. vulgaris $\times P$. coccineus. A number of $\mathrm{F}_{1}$ plants were abnormal and failed to produce seeds. As a result, the number of available $F_{2}$ populations was reduced.

The results of this study indicate that resistance to W. sclerotiorum in B-3749 is associated with blossom tissue. This is an important factor since blossoms are essential as an energy source for the germination of ascospores and development of mycelial growth as well as infection of beans ${ }^{\mathbf{1 , 3} 12}$. However, the mechanism of resistance in the blossoms has not been determined.

Utilizing the ascospore inoculation procedure, several other selections of $P$. coccineus, mostly with colored seeds and flowers, and $P$. vulgaris have been found to be resistant or tolerant to $W$. sclerotiorum. It will be interesting and important to determine whether resistance in all cases is conferred by the same genetic factor or other factors. Furthermore, it is important to determine whether resistance in B-3749 to the mycelial inoculation of the epicotyl tissue ${ }^{6}$ is genetically the same as reported here

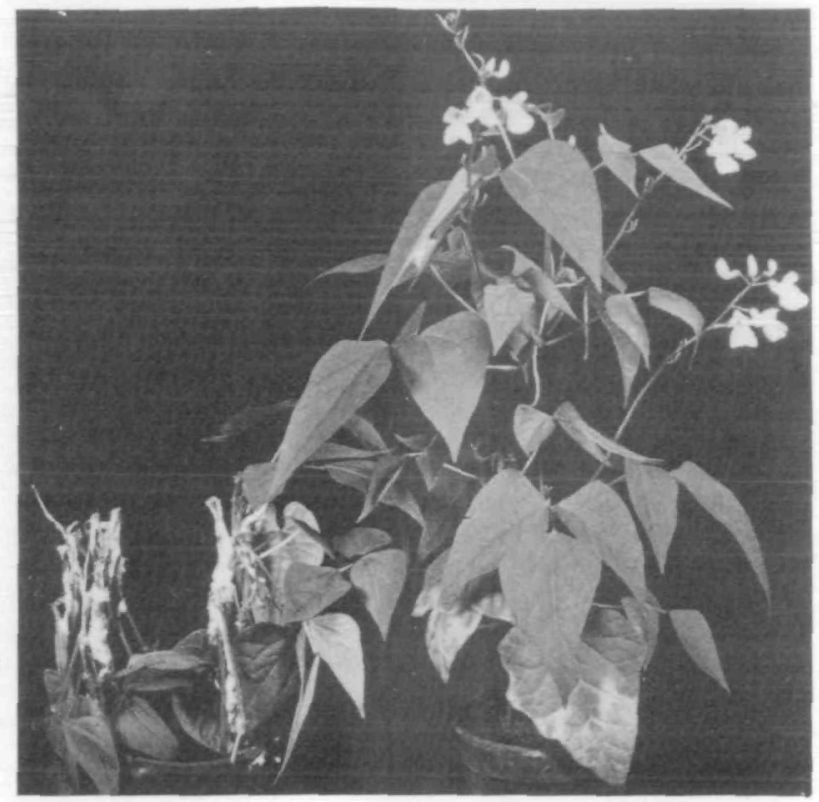

FIGURE 1-Reaction of the snap bean (Phaseolus vulgaris), Bush Blue Lake 274 (left), and Phaseolus coccineus P.I. 175829 (right) to inoculation with ascospores of $W$. sclerotiorum at bloom. Plants were incubated in a mist chamber at $20-24^{\circ} \mathrm{C}$ for 10 days.

for ascosporic inoculation of the blossom tissue. Although line B-3749 was resistant to $W$. sclerotiorum by both methods of inoculation, with other lines a close correlation did not always occur between resistance or tolerance using these two methods.

\section{Summary}

A white-seeded selection of Phaseolus coccineus (P.I. 175829) from Turkey was found to be highly resistant to Whetzelinia sclerotiorum. Intraspecific crosses and backcrosses made with susceptible Phaseolus vulgaris germplasm indicate that a single completely dominant gene governs this high level of resistance. The symbol $W s$ is proposed for this gene. The inoculation procedure used to evaluate bean germplasm simulated natural disease occurrence in commercial bean fields. Plants at the susceptible blossom stage were sprayed with a suspension of ascospores obtained from aseptically produced apothecia. Immediately after inoculation, plants were placed in a mist chamber at $21-25^{\circ} \mathrm{C}$ for one week before final evaluation.

\section{Literature Cited}

1. Abawi, G.S. and R.G. Grogan. Source of primary inoculum and effects of temperature and moisture on infection of beans by Whetzelinia sclerotiorum. Phytopathology 65:300309. 1975 .

2. - and J.E. HunTer. Practical mode of action of benomyl in the control of Whetzelinia sclerotiorum on beans. Proc. XIX Inter. Hort. Congress 1A:279(Abstr.). 1974.

3. - F.J. POLACH, and W.T. MoliN. Infection of bean 
by ascospores of Whetzelinia sclerotiorum. Phytopathology 65:673-678. 1975.

4. - R. Provvidenti, and J.E. Hunter. Evaluating bean germplasm for resistance to Whetzelinia sclerotiorum. Proc. Am. Phytopathol. Soc. 2:50(Abstr.). 1975.

5. - - - R.G. Grogan, and J.E. Hunter. Predisposition of beans to infection by ascospores of Whetzelinia sclerotiorum prior to blossoming. Proc. Am. Phytopathol. Soc. 2:61(Abstr.). 1975.

6. Adams, P.B., C.J. Tate, R.D. Lumsden, and J.P. MEINERS. Resistance of Phaseolus species to Sclerotinia sclerotiorum. Ann. Rep. Bean Improve. Coop. 16:8-9. 1973.

7. Coyne, D.P., J.R. Steadman, and F.N. ANDERson. Effects of modified plant architecture of Great Northern dry bean varieties (Phaseolus vulgaris) on white mold severity, and components of yield. Plant Dis. Reptr. 58:379-382. 1974.

8., , and H.F. SchwarTz. Reaction of Phaseolus dry bean germplasm to Sclerotinia sclerotiorum. Plant Dis. Reptr. 61:226-230. 1977.

\section{Karyological analysis of the Horsfield's shrew from peninsular India}

\section{S. Krishna Rao and N. V. Aswathanarayana}

$T^{H}$ HE Horsfield's shrew, Crocidura horsfieldi, has been described to occur in Ceylon, Kashmir, Indo-China, Siam, Northern Burma and the Liukiu Islands ${ }^{5}$. The occurrence of this species in peninsular India has not been recorded so far. Yosida et al. ${ }^{23}$ reported a diploid chromosome number of $2 n=26$ for this species in animals collected from Okinoerabu Island and Kagoshima (Japan). In this communication detailed karyotypic data of this species from peninsular India are presented.

\section{Materials and Methods}

Six individuals ( 4 males and 2 females) were collected on the environs of the University campus (Manasa Gangotri, Mysore, S. India). The body measurements of all the individuals killed were routinely recorded and are presented in Table I. The animals were injected intraperitoneally with 0.05 percent colchicine. The bone marrow, spleen, intestinal epithelium, and testis were

The authors are research fellow, and reader, respectively, in the Department of Zoology, University of Mysore, Manasa Gangotri, Mysore 570 006, India. They thank Professor M.R. Rajasekarasetty, Department of Zoology, University of Mysore, for encouragement and the use of facilities. They also thank the authorities of the British Museum (Natural History), London, for identifying the specimens. This work was supported by a fellowship (to SKR) and financial assistance (to NVA) from the University Grants Commission, New Delhi.
9. Duniway, J.M., G.S. Abawi, and J.R. Steadman. Influence of soil moisture on the production of apothecia by sclerotia of Whetzelinia sclerotiorum. Proc. Am. Phytopathol. Soc. 4:(Abstr.). 1977.

10. Grogan, R.C. and G.S. ABaWI. The influence of water potential on the biology of Whetzelinia sclerotiorum. Phytopathology 65:122-128. 1974 .

11. HunTER, J.E. and G.S. ABaWI. Factors affecting the efficacy of benomyl in control of white mold of snap beans. Plant Dis. Reptr. 62: in press. 1978.

12. NATTI, J.J. Epidemiology and control of bean white mold. Phytopathology 61:669-674. 1971.

13. Steadman, J.R. and G.E. Cook. A simple method for collecting ascospores of Whetzelinia sclerotiorum. Plant Dis. Reptr. 58:190. 1974.

14. - D.P. CoyNe, and G.E. Cook. Reduction of severity of white mold disease on Great Northern beans by wider row spacing and determinate plant growth habit. Plant Dis. Reptr. 57:1070-1071. 1973. utilized for chromosomal preparations applying the airdry technique. Slides were stained with buffered Giemsa stain ( $\mathrm{pH}$ 6.8). The karyotype was constructed and the chromosomes were classified according to the system proposed by Levan et al. ${ }^{6}$. The morphometric data of the chromosomes are presented in Table II, and an idiogram is presented in Figure 1. The specimens under study were identified as Crocidura horsfieldi Tomes by the British Museum (Natural History), London.

\section{Results and Discussion}

The diploid chromosome number in all the animals killed was 38 (fundainental number, $N F=48$ ) as shown in Figure 3. The karyotype consists of one pair of metacentric (Figure 2, chr. 1), one pair of submetacentric (Figure 2, chr. 2), two pairs of subtelocentric (Figure 2, chr. 3 and 4), and fourteen pairs of telocentric chromosomes in a graded series (Figure 2, chr. 5 to 18). The $\mathrm{X}$ chromosome is metacentric and measures 6.5 percent of the haploid genome; thus it is slightly larger than the original type according to the classification of Ohno

Table I. Body measurements of $C$. horsfieldi

\begin{tabular}{lcccc}
\hline Sex & HB & T & HF & E \\
\hline Female & 58 & 46 & 10 & 6 \\
Male & 62 & 47 & 11 & 7 \\
Male & 63 & 49 & 11 & 7 \\
Female & 61 & 46 & 11 & 7 \\
Male & 56 & 45 & 10 & 6 \\
Male & 53 & 44 & 10 & 6
\end{tabular}

HB, head and body; T, tail; HF, hindfoot; E, ear; all measurements are indicated in millimeters 